\title{
FUNDAMENTOS HISTÓRICOS DA NECESSIDADE DE NOVOS MODELOS DE GESTÃO DA ESCOLA PÚBLICA NO BRASIL
}

\author{
Maria Isabel Moura Nascimento' \\ Isabel Castilho Palhano2 \\ Suzamara Weber $^{3}$
}

\begin{abstract}
RESUMO
O objetivo central deste texto é analisar os fundamentos históricos da necessidade da implantação de escolas militares no Brasil. Assim, historicizamos as origens da educação militar, problematizamos a disputa do espaço escolar na luta pela hegemonia capitalista e por fim, apresentamos e analisamos a contradição entre os princípios militares e os documentos legais da educação. Especificamente refletimos a partir do contexto de conflito que envolve dois colégios públicos no estado do Paraná, a saber: Gildo de Laranjeiras do Sul e Manoel Ribas de Guarapuava. Em ambos os colégios as manifestações de repúdio partiram de estudantes, pais, professores e funcionários, sujeitos envolvidos diretamente com o contexto escolar. Para tanto, tendo como base a perspectiva ontológica marxiana podemos afirmar que novos modelos de gestão da educação pública a partir da imposição de normas da educação militar, ou seja, a transformação da escola pública em colégio militar como se fosse a solução para os problemas da educação, representa um retrocesso para a gestão da educação pública e democrática no Brasil.
\end{abstract}

Palavras-chave: Gestão escolar. Educação militar. Ensino público.

\footnotetext{
1 Doutora em Educação pela Universidade Estadual de Campinas; Professora e orientadora do Programa de Pós-Graduação em Educação da Universidade Estadual de Ponta Grossa Paraná, Brasil; Bolsista de Produtividade em Pesquisa do CNPq - Nível 2; Coordenadora e pesquisadora do projeto de parceria UEPG-Brasil e a Universidade de Unirovuma de Moçambique, que abrange os Programas de Pós-Graduação em Educação de ambas as universidades.OrcidiD:https://orcid.org/0000-0001-6243-9973.E-mail: misabelnasc@gmail.com 2Doutoranda em Educação pela Universidade Estadual de Ponta Grossa - Paraná, Brasil; Professora pedagoga da Educação Básica e do Ensino Profissionalizante Formação de Docentes da rede estadual do Paraná; Participante como pesquisadora do projeto de parceria UEPG-Brasil e a Universidade de Unirovuma de Moçambique, que abrange os Programas de Pós-Graduação em Educação de ambas as universidades. Orcid iD:https://orcid.org/0000-0003-2527-393X. E-mail: pedisabel@yahoo.com.br 3Doutoranda em Educação pela Universidade Estadual de Ponta Grossa - Paraná, Brasil;Professora de Arte na rede estadual do Paraná. Orcid iD: https://orcid.org/0000-00034320-8154. E-mail: suzaweber@yahoo.com.br
} 


\title{
HISTORICAL FOUNDATIONS OF THE NEED FOR NEW MODELS OF PUBLIC SCHOOL MANAGEMENT IN BRAZIL
}

\begin{abstract}
The central objective of this text is to analyze the historical fundamentals of the necessity of implanting military schools in Brazil. Thus, we historicize the origins of military education, problematize the dispute over the school space in the struggle for capitalist hegemony and finally, we present and analyze the contradiction between military principles and legal documents of education.Specifically we reflect on the context of a conflict which involves two public schools in the state of Paraná, namely: Gildo de Laranjeiras do Sul e Manoel Ribas de Guarapuava. In both schools, the manifestations of repudiation came from students, parents, teachers and employees, subjects directly involved with the school context. To this end, based on the Marxian ontological perspective, we can affirm that new models of public education management from the imposition of military education norms, that is, the transformation of the public school into a military college as if it were the solution to the problems of education, represents a setback for the management of public and democratic education in Brazil.
\end{abstract}

Keywords: School management. Military education. Public education.

\section{FUNDAMENTOS HISTÓRICOS DE LA NECESIDAD DE NUEVOS MODELOS DE GESTIÓN DE ESCUELAS PÚBLICAS EN BRASIL}

\section{RESUMEN}

El objetivo central de este texto es analizar los fundamentos históricos de la necesidad de implantar escuelas militares en Brasil.Así, historizamos los orígenes de la educación militar, problematizamos la disputa por el espacio escolar en la lucha por la hegemonía capitalista y finalmente presentamos y analizamos la contradicción entre principios militares y documentos legales de la educación. Específicamente reflexionamos sobre el contexto de un conflicto que involucra a dos escuelas públicas en el estado de Paraná, a saber: Gildo de Laranjeiras do Sul y Manoel Ribas de Guarapuava. En ambas escuelas, las manifestaciones de repudio vinieron de estudiantes, padres, profesores y empleados, sujetos directamente relacionados con el contexto escolar.Para ello, a partir de la perspectiva ontológica marxistapodemos afirmar que nuevos modelos de gestión de la educación pública a partir de la imposición de normas de educación militar, es decir, la transformación de la escuela pública en un colegio militar como si fuera la solución a los problemas de la educación, representa un retroceso para la gestión de la educación pública y democrática en Brasil.

Palabras clave: Escapada escolar. Educación militar. Educacion publica. 


\section{INTRODUÇÃO}

Este texto tem como objetivo analisar os fundamentos históricos da necessidade da implantação de escolas militares a partir do contexto dos Colégios Estaduais Professor Gildo e Manoel Ribas. Resultado de uma sistematização movida inicialmente pela necessidade de historicizar a materialização de um conflito ocorrido em dois Colégios Estaduais: Colégio Professor Gildo Aluísio Shuck em Laranjeiras do Sul e Colégio Manoel Ribas em Guarapuava, ambos do estado do Paraná. No Colégio Gildo a movimentação de repúdio a instalação começou pela comunicação do Chefe do NRE - Núcleo Regional de Educação em reunião com diretores, informando que o colégio estava sendo avaliado entre outras escolas pela Policia Militar para a instalação de uma escola militar na cidade de Laranjeiras do Sul, sendo o principal argumento que o referido Colégio se localizava na região central da cidade, local que distribuiria a distância entre os bairros.

A informação que liderança política local estaria pleiteando junto ao governo do estado uma escola militar, chegou a comunidade escolar, alunos, pais, professores e funcionários sem antes uma consulta do interesse destes em fazer parte desse tipo de educação e desse modelo de gestão. A única consulta que foi realizada pela chefia do NRE foi de sondagem da aceitação pelas instituições privadas do comércio e associações da sociedade civil local.

No colégio Manoel Ribas o primeiro contato foi feito por parte da chefia do NRE de Guarapuava, para a direção do colégio, argumentando estar fazendo uma sondagem, pois é um espaço em potencial além de ter localização central. Após essa comunicação a direção convocou a comunidade para realizar consulta, pais, alunos, funcionários e professores se posicionaram contrários a instalação de um colégio militar no espaço do Manoel Ribas. A informação de lideranças políticas da região foi de que a comunidade estaria pleiteando junto ao governo do estado a instalação de escola militar em Guarapuava. 
Ações que na interpretação de Oliveira (2016), ao analisar as escolas militares em outros estados brasileiros, entre estes, o autor cita o de Goiás, onde explicita como controle, cultura do medo e da violência, afirma que no atual contexto político e social, essa iniciativa trata-se de mais uma agenda conservadora embusca de manter a hegemonia política. Diante da manifestação de interesses privados como regra para aceitação social dessas escolas militares, identifica-se que sua necessidade tem se transformadoem uma troca eleitoral. Elas surgem como manifestação dedesejo de prefeitos que tem pouco a oferecer em termos de qualidade na educação, uma vezque, estas escolas militaressão proporcionadas como concessões do Governo como troca de favores entre aliados. Nas palavras de Silva (2016, p. 93), "na perspectiva histórica, os corpos policiais nasceram mediante a manutenção de interesses de oligarquias locais".

Esse foi o contexto em que surgiu o conflito entre os Colégios citados com 0 Estado, o qual se problematiza no decorrer deste artigo. Nossa principal pergunta é porque os governantes entendem como necessária a implantação de escolas militares sendo que a comunidade escolar, estudantes, pais e professores repudiam tal ação?

E por acreditarmos que, para haver rigor e seriedade nos processos de produção do conhecimento é que assumimos a perspectiva ontológica marxiana, no entendimento de que não podemos esquecer o ponto de vista de classe social, ou seja, essa luta que por mais que muitas vezes, a classe dominante fizesse esforço em esconder sempre esteve presente na construção do conhecimento no decorrer da história.

Portanto, é nas contradições da realidade e na objetivação da teoria que se produz a veracidade de um determinado conhecimento, diante disso, investigar a implantação de escolas militares nas suas especificidades requer cuidado em considerar as condições materiais da qual esta se constituiu no decorrer da história. Como afirma Marx (2014), "o primeiro pressuposto de toda a história humana é naturalmente, a existência de indivíduos humanos vivos". Neste sentido, "toda a historiografia deve partir desse fundamento natural e de sua modificação pela ação dos homens no 
decorrer da história". Ou seja, "O que eles são coincide, pois com sua produção tanto com o que produzem como também com o modo como produzem. O que os indivíduos são, portanto, depende das condições naturais de sua produção" (p. 87). Por isso, a importância da investigação desse modelo de gestão educacional diante do conflito de classe na atualidade.

Enfim, é a partir destas categorias acima discorridas que se fundamenta o método desta pesquisa, princípios teóricos-metodológicos que serão fundamentais para o aprofundamento dos conceitos por meio de pesquisa teórica, bibliográfica relacionada a militarização das escolas brasileiras, bem como também, na análise das fontes, como atas transcritas pelo Conselho Escolar dos Colégios Professor Gildo e Manoel Ribas. Materiais estes que deram base empírica para a elaboração deste artigo, possibilitando assim o cruzamento dos dados relacionando algumas categorias relevantes na materialidade da investigação, para então, evidenciar o pensamento pedagógico filosófico do modelo de gestão da escola militar.

\section{A ORIGEM DA EDUCAÇÃO MILITAR}

Para historicizar a institucionalização da educação militar, vamos nos remeter antes a categoria marxiana trabalho, que para Marx (2014), o trabalho que garante a existência enquanto ser vivo, pois antes de tudo os homens precisam para viver, comer, vestir, morar entre outras necessidades, e a partir do fato de suprirem estas necessidades vão produzindo história. Assim estes se constituem com aquilo que produzem e com o modo que produzem, sendo resultado dessas circunstâncias materiais e ao produzir essas circunstâncias conscientes modificam o meio natural e a si mesmo enquanto homem, "o homem, enquanto homem, é social, isto é, está moldado por um ambiente histórico de que não pode ser separado" (PONCE, 1982, p. 20).

Para Ponce (1982), dessas circunstâncias de trabalho que emergem a concepção de educação de cada momento histórico, oriunda de seus 
indivíduos enquanto ocupações na produção de sua existência que se deriva o ideal pedagógico, como raiz de uma determinada educação.

E que nas sociedades primitivas essa educação se apresentava de forma difusa e que as crianças iam aprendendo pela imitação daquilo que os adultos praticavam para produzirem sua existência, "a educação não estava confiada a ninguém em especial, e sim à vigilância difusa do ambiente" (PONCE, 1982, p. 18), porém, essa forma difusa de educar suas futuras gerações se mostrou insuficiente, quando começa a tratar de disputas e proteções de territórios.

Nesse processo histórico devido ao crescimento de natalidade a própria comunidade apresentava-se insuficiente na capacidade de produção de alimentos para seus integrantes, chegando ao ponto de quando um grupo tribal vencia a outra além de apropriar-se de suas riquezas, perceberam que era menos catastrófico aprisionar os inimigos do que matá-los. Nesse sentido, logo perceberam que o bem-estar da tribo aumentava pelas novas técnicas de produção trazidas pelos prisioneiros de guerras, logo esse inimigo vencido passava a ser a possibilidade de avanço e também a possibilidade de transformar esse em escravo. "Agora, incorporar indivíduos estranhos à tribo, para explorar o seu trabalho, era, ao mesmo tempo, necessário e possível" (PONCE, 1982, p. 25).

Momento da história humana segundo esse autor, que se transforma a sociedade comunista primitiva em classes sociais, diante disso, a educação assume fins específicos, num primeiro momento contra as tradições do comunismo tribal, inculcando ideias justificando a função das classes dominantes em proteger a vida dos dominados, na vigilância atenta em coibir qualquer atitude de protesto de iniciativas dos oprimidos.

Constatação da qual Saviani (2007), afirma ter dado a origem da escola. "A educação dos membros da classe que dispõe de ócio, de lazer, de tempo livre passa a organizar-se na forma escolar, contrapondo-se à educação da maioria, que continua a coincidir com o processo de trabalho" (p. 156). Com a divisão dos homens em classes consequentemente ocorre a divisão também na educação. Levando a cisão na unidade da 
educação da qual antes era plenamente integrada ao processo do trabalho.

E para além de usufruir desse ócio "digno" esses nobres, contudo, também se preocupavam em continuar a ser, antes de tudo, principalmente homens das armas, pois isso, que lhes davam garantia de poder. Portanto, na Grécia, aproximadamente uns 600 anos A.C., essa preocupação era também levada para as práticas educativas de suas crianças, estas que frequentavam,

[...] ao campo de esportes de manhã ou à escola de música no período da tarde, os seus filhos passavam alternadamente das mãos do citarista às do paidotriba. A primeira denominação ilustra de imediato certos aspectos da educação infantil, mas muito mais interessante é a segunda - que em grego significa 'castigador de crianças' -, que mostra claramente ter o ensino militar perdido muito pouco da sua antiga rudeza (PONCE, 1982, p. 49).

Assim, as cerimônias de iniciação militar deixam de ser um processo educativo espontâneo, mas sim coercitivo. A educação violenta organizada e sistematizada aparece quando perde seu caráter primitivo hegemônico e integral neste caso, porém essa educação se apresenta com a função de inculcar em seus estudantes não mais o que seria necessário para uma finalidade do bem comum, a não ser que 'esse bem comum' fosse justificado como necessário no intuito de afirmar as classes dominantes. "Para estas, a riqueza e o saber; para as outras, o trabalho e a ignorância" (PONCE, 1982, p. 28).

Com isso foi se consolidando uma classe compacta de soberanos, magos, sacerdotes e guerreiros que passaria então a constituir interesses comuns, e na maioria das vezes opostos aos demais do grupo. E para efetivar essa consolidação de classe surge uma instituição como garantia de sua perpetuação.

Mas, ainda estava faltando alguma coisa: uma instituição que não só defendesse a nova forma privada de adquirir riquezas, em oposição às tradições comunistas da tribo, como também que legitimasse e perpetuasse a nascente divisão em classes e o 'direito' de a classe proprietária explorar e dominar os que nada possuíam. E essa instituição surgiu: o Estado (PONCE, 1982, p. 32). 
Nesse sentido Mészáros, enfatiza que a igualdade prometida por esse Estado liberal não passa do plano ideal, pois na sua essência tem como função proteger a divisão de classe.

\begin{abstract}
Mas é claro que nada poderia ser mais estranho para 0 funcionamento do sistema do capital em sua crise estrutural do que a instituição da igualdade real. Pois ele é constituído como um sistema de hierarquias estruturalmente entrincheiradas que deve ser protegido de todas as maneiras por suas formações de Estado (2015, p.27).
\end{abstract}

Para o autor a organização do capital se apresenta em três pilares de sustentação: "capital, trabalho e Estado". Desses nenhum pode sereliminado de forma independente. "A materialidade do Estado está profundamente enraizada na base sociometabólica antagônica sobre a qual todas as formações de Estado do capital são erguidas" (MÉSZÁROS, 2015, p.29). E que na atualidade este Estado tem assumido cada vez mais uma função vital como principal articular direto e avassalador na intervenção enquanto tomada de decisão global.

Nessa mesma perspectiva Ponce (1982), afirma que estreitamente à estrutura econômica das classes sociais está ligada a educação, ou seja, para cada momento histórico, a educação é reflexo necessário dos interesses e aspirações da classe dominante. "Revoluções no campo educativo, não vimos mais do que duas: quando a sociedade primitiva se dividiu em classes e quando a burguesia do século XVIII substituiu e Feudalismo" (p.159). E numa interpretação marxiana do conceito da evolução da própria história o autor vai além relacionando a função primordial da educação na formação da mentalidade e da conduta das crianças.

O conceito da evolução histórica como um resultado das lutas de classes nos mostrou, com efeito, que a educação é o processo mediante o qual as classes dominantes preparam na mentalidade e na conduta das crianças as condições fundamentais da sua própria existência. Pedir ao Estado que deixe de interferir na educação é o mesmo que pedir-lhe que proceda dessa forma em relação ao Exército, à Polícia e à Justiça. [...] A classe que domina materialmente é também a que domina com a sua moral, a sua educação e as suas ideias. Nenhuma reforma pedagógica 
fundamental pode impor-se antes do triunfo da classe revolucionária que a reclama [...] (PONCE, 1982, p. 165).

Portanto, para o autor, nesses moldes educacionais, o indivíduo deve ser manso, respeitoso, ordeiro e discreto, dominado. Então feito esse resgate histórico da origem da educação como meio para perpetuar a divisão de classe, é que tomaremos como fundamento para a discussão a seguir da necessidade da implantação de escolas militares como referência possível de eficiência na educação atual.

\section{A DISPUTA DO ESPAÇO ESCOLAR NA LUTA PELA HEGEMONIA CAPITALISTA}

A educação em seu sentido amplo sempre foi uma necessidade humana desde os primórdios da história, como afirma Mészáros (2008), esta que acontece desde o nascer até morrer, no entanto, com o advento da modernidade, a educação passa a ser uma necessidade para o desenvolvimento capitalista, nesse sentido, retoma-se aqui a categoria trabalho para compreender o contexto das reformas educacionais. $O$ trabalho como afirma Marx (2012), no seu sentido ontológico produz a existência humana, mas na sua contradição de classe produz estranhamento e alienação, e que para a sua perpetuação enquanto exploração há necessidade de se reproduzir como tal. Para essa reprodução e perpetuação da exploração, a educação institucionalizada assume uma função protetora do sistema capitalista, como coloca Mészáros.

\footnotetext{
Isso não pode ser feito sem desafiar as formas atualmente dominantes de internalização, fortemente consolidadas a favor do capital pelo próprio sistema educacional formal. De fato, da maneira como estão as coisas hoje, a principal função da educação formal é agir como um cão de guarda ex-officio e autoritário para induzir um conformismo generalizado em determinados modos de internalização, de forma a subordiná-los às exigências da ordem estabelecida (2008, p. 55).
}

Função internalizadora de validação e aceitação da condição de explorado enquanto classe trabalhadora, que nessa perspectiva do reino 
capitalista onde tudo é para negócio, a própria educação torna-se mercadoria, retirando assim a atribuição humanizada.

E para atender tais orientações de um currículo homogeneizante propõe-se projetos de leis que tiram a autonomia docente, como afirma Frigotto (2017), quando problematiza o Projeto de Lei Escola sem Partido.

Escola sem Partido expressa o epílogo de um processo que quer instituir uma lei que define o que é ciência e conhecimento válidos, e que os professores só podem seguir a cartilha das conclusões e interpretações da ciência oficial, uma ciência supostamente não neutra. Para isso, manipula até mesmo o sentido liberal de política, induzindo a ideia de que a escola no Brasil estaria comandada por um partido e seus profissionais e os alunos seres idiotas manipulados (p. 29).

Tira-se do professor no processo educativo, a autonomia de ensinar e avaliar em nome dessa neutralidade, mas segundo o mesmo autor, essa questão da neutralidade tem seus fundamentos ligados a fatores de uma crise mundial que não é mais cíclica, mas permanente e continua cada vez mais profunda. "Para manter seus lucros tem que aumentar a desigualdade e as mais diferentes formas de violência, no limite pela eliminação de quem se opõe. Disto decorre a mudança de estratégias para legitimar a violência do Estado" (p. 30). Diante disso, com o argumento de combater o terrorismo usa a força policial do Estado, que em nome da justiça antes tende a criminalizar seu adversário como inimigo afirmando que este ameaça risco para a segurança pública, motivo que a princípio justifica sua condenação. "Do Campo da guerra e do terrorismo, avança-se na criminalização dos movimentos sociais, culturais, sindicais e políticos que se opõem à violência da desigualdade, exclusão de direitos e do pensar divergente" (p.30). Então é esse pensar diferente que incomoda os representantes do capital, pois vão questionar e denunciar a profunda violência contra a classe trabalhadora, como afirma o autor esse é o enigma que fundamenta a tese da Escola sem Partido. Disso então se deriva a necessidade de ensinar-se o científico neutro nas escolas. 
Nesse sentido, Frigotto (2017) ainda vai além na reflexão, afirmando que a ditadura do capital sustentada pela burguesia brasileira egoísta, cínica e violenta se organizou e concretizou o golpe contra a institucionalidade democrática da soberania do voto popular. Burguesia que se valeu do mercado religioso da "boa-fé" principalmente dos trabalhadores que se apresentam mais expropriados de elementos de discernimentos, classe que Ihes foram negados historicamente o acesso à educação básica, estes expostos a forças de corporações empresariais da mídia, agem como "moedores de cérebros" na consolidação de verdades, que são voltados a interesses da classe dominante dos quais promoveram o golpe. "A relação entre os mecanismos jurídicos formais que sustentaram e consumaram 0 golpe e as teses da Escola sem Partido de incriminar os docentes tem na delação, com base no arrependimento ou discordância moral, seu fundamento mais ardiloso e perverso [...]". No entanto, isso fica evidente que a essência do Projeto como a Escola sem Partido apresenta uma profunda confusão ética dos conceitos religiosos e jurídicos.

E como consequência disso, o referido projeto liquida a função docente, pois estes irão somente executar o que prescreve as apostilas e manuais de ensino, "a pedagogia da confiança e do diálogo crítico é substituído pelo estabelecimento de uma nova função: estimular os alunos e seus pais a se tornarem delatores" (FRIGOTTO, 2017, p. 31). Pois aqueles que denunciarem a exploração ou reivindicarem direitos sociais serão classificados como bandido. Contexto que já tem apresentado sinais de materialidade na prática, movidos pelo medo e pela violência coercitiva das cobranças sobre a ação docente.

E nesse viés do discurso do conteúdo neutro os professores deverão trabalhar só que está previsto como currículo padronizado, pressionados a cumprir com as metas, estes deverão reproduzir o já pensado desconsiderando o contexto escolar local. Uma vezque, estes professores não alcancem as ditas metas, sentirão-se envergonhados e culpados pelo fracasso. Não bastando isso, seu salário estará atrelado aos índices das provas externas segundo o princípio da meritocracia, caso não se alinhar as 
exigências da flexibilização do trabalho será "demonizado" e odiado pelos seus superiores. Portanto, atrelado ao discurso do trabalho "neutro" e da "meritocracia" dos resultados, o trabalho docente se torna uma mercadoria, ou seja, um trabalho estranhado e alienado, como afirma Marx (2010), em seu texto Manuscritos econômico-filosóficos.

O trabalhador se torna tanto mais pobre quanto mais riqueza produz, quanto mais a sua produção aumenta em poder e extensão. $O$ trabalhador se torna uma mercadoria tão mais barata quanto mais mercadorias cria. Com a valorização do mundo das coisas aumenta em proporção direta a desvalorização do mundo dos homens. 0 trabalho não produz somente mercadorias; ele produz a si mesmo e ao trabalhador como uma mercadoria [...]. O trabalho produz, o seu produto, se the defronta como um ser estranho, como um poder independente do produtor [...] (p. 80).

Nesse entendimento, Mészáros (2005), enfatiza de que, no reino do capital, a própria educação é uma mercadoria.

Daí a crise do sistema público de ensino, pressionado pelas demandas do capital e pelo esmagamento dos cortes de recursos dos orçamentos públicos. Talvez nada exemplifique melhor o universo instaurado pelo neoliberalismo, em que 'tudo se vende, tudo se compra', 'tudo tem preço', do que a mercantilização da educação. Uma sociedade que impede a emancipação só pode transformar os espaços educacionais em shopping centers, funcionais à sua lógica do consumo e do lucro (p. 16).

Diante disso o autor vai além na sua reflexão quando coloca que, a razão para o fracasso de muitos esforços de reformas educacionais numa perspectiva de reconciliadora das classes sociais, apresenta-se limitada pelo fato de que existem determinações estruturais fundamentais próprias do sistema capitalista que são irreformáveis. Isso explica o fracasso de muitas tentativas de democratização da educação e do trabalho na perspectiva humanizadora.

[...] digam-me onde está o trabalho em um tipo de sociedade e eu te direi onde está a educação. Em uma sociedade do capital, a educação e o trabalho se subordinam a essa dinâmica, da mesma forma que em uma sociedade em que se universalize o trabalho uma sociedade em que todos se tornem trabalhadores -, somente aí se universalizará educação (MÉSZÁROS, 2005, p. 17). 
Ao expor esse contexto de reorganização mundial da função escolar dentro de uma demanda capitalista, o formato da educação escolar militar vem ao encontro dos requisitos dessa nova função, como afirma Mészáros (2015), o papel do Estado para garantir a divisão de classe.

Diante disso, esse formato de escolas geridas por militares efetiva-se na materialidade da lógica pensada a décadas enquanto política educacional para o Brasil.

\begin{abstract}
Nessa conjuntura, o Brasil iniciou, em 1995, A Reforma Gerencial do Estado brasileiro através do Ministério de Administração Federal e Reforma do Estado (MARE); e, entre 1995 a 1998, o papel do Estado foi reformulado a priori na esfera federal. A frente do MARE, Luiz Carlos Bresser-Pereira, então Ministro da Fazenda, nos primeiros quatro anos do governo FHC formulou as propostas da Reforma Gerencial do Estado de 1995. As propostas apresentadas por BresserPereira foram pautadas na administração por resultados, ou seja, trouxe a metodologia de funcionamento das empresas privadas para a burocracia estatal, com a justificativa de tornar o Estado mais eficiente no que tange à prestação de serviços de monopólio do Estado - como saúde, educação e segurança -, com a desculpa de que $O$ Estado não conseguia ofertar serviços de qualidade (GUIMARÃES; LAMOS, 2018, p. 71).
\end{abstract}

O que se evidencia nesse contexto, são os fundamentos políticos e ideológicos de uma reforma neoliberal, que culminou em uma reforma gerencial do Estado brasileiro, que vem se desdobrando em uma série de outras reformas, entre estas, uma das mais significativas é a reforma educacional. Fundamentos que trazem na sua essência a lógica privada de gestão respaldada em resultados de uma formação para empregabilidade, que demanda a flexibilização das relações de trabalho de acordo com o mercado capitalista.

A proposta apresentada por Bresser-Pereira foi pautada na administração por resultados, ou seja, trouxe a metodologia defuncionamento das empresas privadas para a burocracia estatal, com a justificativa de tornar o Estado mais eficiente no que tange à prestação de serviços de monopólio do Estado - por exemplo: saúde, educação e segurança -, com a desculpa de que o Estado não conseguia ofertar serviços de qualidade (GUIMARÃES; LAMOS, 2018, p. 71). 
De acordo com a nova proposta desse modelo de gestão do trabalho pedagógico na educação escolar uma série de problemas deveriam ser superados, entre estes a repetência, a evasão, a indisciplina e consequentemente a diminuição da violência. Aqui nessa afirmação evidenciam-se alguns questionamentos, pois algumas décadas já se passaram e os índices não melhoram e nem a violência foi resolvida, motivos que vão justificar a necessidade de a Polícia Militar tornar-se responsável pela administração de uma escola pública. "Cabe destacar que as escolas selecionadas estão localizadas em sua maioria na periferia, onde há altos índices de homicídios e com baixos índices de aproveitamento no Exame Nacional do Ensino Médio (ENEM)" (GUIMARÃES; LAMOS, 2018, p. 73). Entretanto, os autores citados afirmam que, entre os motivos apresentados oficialmente no argumento da necessidade dessas escolas militares, apresentam a violência escolar e o baixo rendimento dos alunos, no entanto há de se considerarque o segundo problema o baixo rendimento está diretamente relacionado ao primeiro o da violência escolar.

\section{A CONTRADIÇÃO ENTRE PRINCÍPIOS MILITARES E OS DOCUMENTOS LEGAIS DA EDUCAÇÃO}

O surgimento de instituições, como escolas militares têm sua gênese no contexto que coincide com a constituição da própria República brasileira. Historicizado por Castro (2016), em 1889 oficializa-se pelo Decreto Imperial 10.202, o primeiro Colégio do Exército na cidade do Rio de Janeiro, o Imperial Colégio Militar da Corte, a abertura desse colégio tinha como objetivo atender os filhos de militares, no entanto, nesse contexto também já existia a discussão que indicava a necessidade de organizar a educação formal no viés militar para os filhos de não militares. Por mais que existissem críticas acerca de despesas excessivas desses colégios. "Em 1912, surgem Colégios Militares nas cidades de Porto Alegre-RS e Barbacena-MG, fato que força a mudança do nome da escola para Colégio Militar do Rio de Janeiro. Destaco que, somente em seu centenário, no ano de 1989, o colégio passa 
a aceitar jovens do sexo feminino em suas turmas de ensino fundamental e médio" (p.32).

Sendo que a mesma autora, destaca que em 2016, a maioria dos estados já possui instituições de Educação Básica com gestão de militares, contabilizando 93 colégios em dezoito estados da nação brasileira. "Os estados que primeiro criaram colégios da polícia militar foram Bahia (1957), Paraná (1959) e Pernambuco (1966) (p. 33). O que a pesquisadora chama atenção é o fato de que o estado de Goiás ter em 2013 dobrado o número de escolas no intervalo de alguns meses e havendo ainda dezenas de solicitações de aberturas de novas unidades no modelo CPM - Colégios da Polícia Militar em diversos municípios. Nesse sentido o que se deve observar é que,

Essa ampliação repentina, considerado o contexto anterior à criação dos novos colégios, passa a colocar milhares de jovens sob um modelo de educação militar. A experiência não apenas perde seu caráter mais pontual, como informa a existência de um expressivo modelo paralelo de Educação, que envolve a presença de uma instituição com concepções, normas, valores e procedimentos calcados em referências simbólicas e identidade própria (CASTRO, 2016, p. 34).

Diante disso, o trabalho do cotidiano é marcado por conceitos e valores de sociabilidade distintos.

Na análise de Oliveira (2016), a educação militarista tem se destacado no decorrer da história como uma metodologia educativa que se pressupõe eficiente e que se apresenta em formas de treinamentos duros e violentos e sempre baseados nos princípios da disciplina e hierarquia, com a justificativa de preparar para a vida.

A cultura do medo e a prática militarista tendem a vender a ideia de que a militarização é uma solução para ampliar a segurança, além de servir de combate à violência. Essa foi uma das teses espalhadas pelo Estado. Não é verdade. Política de segurança se faz com justiça social. O processo de militarização das escolas é parte do processo de ampliação do controle social [...] (2016, p. 49).

Nesse viés Veloso e Oliveira (2016), destacam que a hierarquia e disciplina integrada apresentam-se como potencial quaseilimitado de 
obediência desses subordinados. "Um indivíduo socializado dentro de uma instituição dessa espécie tende a perder a sua capacidade crítica, tornando-se um mero cumpridor de ordens" (2016, p. 75).

Feita essa constatação histórica, a primeira pergunta que se deve fazer é: a escola nesses moldes tem constitucionalidade sob a gestão de militares? Ou melhor dizendo a militarização de escola tem amparo jurídico? Uma escola pode ser militar? Para responder a essas indagações vamos recorrer as leis maiores que amparam o processo educativo público, que garantem o direito de todos, tanto crianças quantoadultos, o acesso, permanência e sucesso escolar, documentos que são: a Constituição Federal de 1988; Leide Diretrizes e Bases da Educação de 1996 e o Plano Nacional de Educação de 2014.

Para começar, vamos examinar a Constituição Federal quando se refere acerca da gestão do ensino, onde prevê no artigo 206, inciso VI. O princípio da "gestão democrática do ensino público", para aprofundar essa análise Tavares (2016), faz a seguinte reflexão acerca da efetivação da gestão democrática.

Cabe à figura que ocupa a direção da escola, seja um oficial, seja quem for cumprir as decisões da comunidade. Quem conhece tão bem de hierarquia como um/a policial militar poderia aproveitar para cumprir bem a decisão daquele que hierarquicamente, segundo a Constituição da República, dispõe sobre as decisões didático-pedagógicas, administrativo-gerenciais, de uma escola. Que são: pais, estudantes e comunidade. De um modo bem simples: quem decide sobre o regimento disciplinar, as opções pedagógicas, o vestuário dos estudantes e todos os detalhes de uma escola pública é a respectiva comunidade, constituída de pais/mães, mestres e estudantes. O/a militar que se comportar em descompasso com esta premissa estará a malferir a Constituição da República e, portanto, cometerá falta grave(p. 56).

Portanto, a gestão escolar para ser democrática, as decisões devem ser tomadas pelo seu público, no caso, estudantes, pais e mestres. Caso contrário, será uma desobediência a lei federativa. E ainda o que é mais grave nisso, é em relação ao princípio da gratuidade, a Constituição Federal prevê em seu art. 206 a gratuidade do ensino em suas instituições oficiais, tendo em vista, que as escolas sob gestão militar tem a prática de 
cobranças de taxas como contribuições voluntárias, como evidencia-se na análise de Tavares afirmando que.

\begin{abstract}
O Estado não vive, portanto, de contribuições voluntárias. Não existe isso na nossa ordem jurídica. E se ele está, portanto, recebendo contribuição voluntária, isso é uma ilegalidade, porque, por via transversa, você está malferindo o princípio da gratuidade do ensino público. [...] Se uma família, ainda que sob suposta espontaneidade, repassa valores mensais, por menores que sejam, para a escola onde suas crianças estudam, então não se trata de ensino gratuito e, portanto, está violada a Constituição da República. O Militar que aceita receber valores informais de particulares, sem que esse dinheiro integre a contabilidade pública, está a contribuir para o vilipêndio do princípio da gratuidade do ensino público e, destarte, comete falta grave(2016, p. 56-57).
\end{abstract}

Para Guimarães e Lamos (2018), aquestão é paradoxal enquanto projeto de militarização das escolas, pois essa cobrança de taxas como contribuição voluntária se tornou alvo de críticas por parte da comunidade escolar. Pelo fato de que essas instituições a princípio teriam que ter como mantenedor unicamente o Estado, diante disso, cobranças se apresentam como indevidas. "Os prédios das escolas já estão construídos, e a manutenção deles é feita pelo Estado, que também paga o salário dos professores. E essa taxa fere, também, os dispositivos legais da Lei n 9.394/96 que versa sobre o "ensino público" e "gratuito" como uma das responsabilidades do Estado" (p. 76). Como evidencia-se no Art. $3^{\circ}$ da LDB n ${ }^{\circ}$ 9.394/96 que apresenta como base os seguintes princípios:

Igualdade de condições para o acesso e permanência na escola; [...] liberdade de aprender, ensinar, pesquisar e divulgar a cultura, o pensamento, a arte e o saber; [...] pluralismo de ideias e de concepções pedagógicas; [...] respeito à liberdade e apreço à tolerância; [...] gratuidade do ensino público em estabelecimentos oficiais; [...] gestão democrática do ensino público; [...] vinculação entre a educação escolar, o trabalho e as práticas sociais (2017, p. 09).

Assim sendo, para respeitar os princípios das constituições e demais leis que regulamentam a oferta da educação pelo Estado em suas instituições de ensino, uma escola militar teria que atender a esses princípios, no 
entanto, o da gestão democrática e da absoluta gratuidade são os fundamentais na materialidade dessa oferta enquanto serviço público.

Nesse viés de análise, quando se recorrea documentos internacionais encontra-se como medida de proteção a não exposição de crianças e adolescentes em práticas militares. "Porque existe uma convenção da ONU e, mais do que isso, existe o artigo 38 da Convenção dos Direitos da Criança - que prescreve (ou seja, não permite) o chamado "soldado criança" (TAVARES, 2016, p. 58). Isso significa, que as crianças e adolescentes não devem vivenciar essas práticas sob cuidados de militares, pois esses não estão preparados para lidar com o trato pedagógico disciplinar nas diversas faixas do desenvolvimento físico e intelectual de crianças e adolescentes. Como Tavares evidencia.

\begin{abstract}
De modo bem claro, veja-se o que dispõe o parágrafo quinto do artigo 144 da Constituição: "às polícias militares cabem a polícia ostensiva e a preservação da ordem pública". A única função adicional - e de caráter excepcional - prevista para as PMs no direito brasileiro é aquela que a própria Constituição, agora no parágrafo 60 do artigo 144, dispõe. O texto é o seguinte: "As polícias militares e corpos de bombeiros militares, forças auxiliares e reserva do Exército...". Fica claro, portanto, que a PM, licitamente, só pode exercer três tipos de atividade: 1) Policiamento ostensivo; 2) Manutenção de lei e ordem e; 3) compor as forças auxiliares e a reserva do Exército. Não cabe à Polícia Militar, portanto, sob nenhuma hipótese, ministrar, gerir, organizar, fornecer ou lidar, direta ou obliquamente, com o serviço de educação pública (2016, p. 61).
\end{abstract}

Diante disso, a contradição está posta, pois quem deveria aplicar na integralidade a lei, estará transgredindo-a, nesse sentido, como que estes profissionais deverão ensinar a respeitar a Constituição se estes estão desrespeitando na sua atuação prática.

No entanto, existem argumentos que tem forças de convencimento da importância dessas escolas no atual contexto educacional e social. "Já aqueles que defendem a militarização das escolas pontuam benefícios como a redução da violência dentro da escola e maior rendimento escolar, fatores que podem ser atribuídos à própria disciplina e hierarquia - pilares do militarismo que são aplicados a tais escolas" (SILVA, ARAUJO, 2018, p. 4). Outro argumento que se apresenta, é a questão das notas de avaliações 
externas, como Castro (2016), coloca em relação as escolas militares de Minas Gerais.

\begin{abstract}
Em segundo lugar, os resultados que as escolas da Polícia Militar mais antigas apresentavam nas chamadas avaliações externas, como o IDEB (Índice de Desenvolvimento da Educação Básica) e o ENEM (Exame Nacional do Ensino Médio) superavam aqueles das demais escolas públicas, colocando-as assim, como exemplo de "sucesso" educacional. O CPMG Dr. Cézar Toledo, por exemplo, localizado no município de Anápolis, alcançou a maior nota na prova do IDEB entre as escolas públicas do estado no ano de 2013, fazendo do colégio notícia em diversos jornais locais. O CPMG Polivalente Modelo Vasco dos Reis, o mais antigo de todos os colégios geridos pela polícia, tinha a melhor média de notas no ENEM entre as escolas públicas do estado. Essas informações eram também centrais no discurso oficial de defesa do modelo CPMG e de sua expansão (p.18).
\end{abstract}

Mas esse rendimento é evidente que é resultado do formato disciplinar existente dentro dessas instituições, pois quem não se enquadra no rigor das condutas exigidas acaba pedindo a transferência para outra escola.

Diante disso, podemos nos respaldar na legislação como direito a inclusão e a diversidade, como observa-se no Estatuto da Criança e do Adolescente de 1990 (ECA), que garante o direito à igualdade de condições para $\circ$ acesso e a permanência na escola,sendo possível se contrapor ao discurso de que todos têm direito a uma vaga na educação militar. Inclusive o argumento da própria ampliação do tempo de permanência das crianças e jovens na escola e o número de atividades ofertadas em um colégio militar. Isso não quer dizer que se amplie a oferta para todos, uma vez que atividades devem ser mantidas financeiramente pela comunidade sendo incompatível com a possibilidade financeira da classe trabalhadora.

Outro aspecto discutível em relação ao acesso à educação para todos, está no fato de que no caso de não cumprimento das normas e princípios da educação militar, o estudante é convidado a se retirar do espaço, isso está em contradição com a garantia da inclusão de todos e a diversidade de ideias no espaço escolar já garantidos pelas leis vigentes da educação brasileira.

No entanto, diante do exposto evidencia-se a disputa do espaço escolar na luta pela hegemonia capitalista, e nessa conjuntura, que no 
entendimento da totalidade do sistema capitalista analisa-se o conflito da instalação da educação militar no Colégio Estadual Professor Gildo Aluísio Schuck, conforme o relato em Ata de n 02/2019 do Conselho Escolar que descreve uma reunião juntamente com a Chefia do NRE de Laranjeiras do Sul, professor Lídio dos Santos, momento que foram cobradas pelos membros do Conselho Escolar mais informações acerca da possibilidade da instalação deste modelo de educação, haja visto, que a comunidade escolar em enquete realizada por representante do NRE se manifestou contraria a efetivação desta proposta no colégio. Nesse sentido, o Conselho Escolar questionou o porquê da escolha desta instituição, indagado professor Lídio responde que foi encaminhado junto a SEED o nome de duas instituições de ensino para análise, sendo que a decisão só será anunciada com a visita de representante da Polícia Militar. A comunidade escolar não ficou contente com 0 encaminhamento deliberado nesta reunião, ocorrendo nos dias seguintes várias manifestações contrarias a instalação do referido Colégio Militar por parte do Grêmio Estudantil, cartazes, abaixo assinado com aproximadamente 2000 assinaturas e como ponto alto disso, um ato em frente ao colégio que levou os estudantes a fecharem a instituição impedindo os profissionais de adentrarem no local.

Ações que repercutiram nas redes sociais, até chegou o dia da visita do representante da Polícia Militar e juntamente com o Chefe do NRE e o Prefeito da cidade de Laranjeiras, sai então a esperada decisão de que a instalação do Colégio Militar não seria nesta instituição e que a prefeitura iria então doar outro prédio para essa nova oferta educacional.

No Colégio Manoel Ribas, assim que houve comunicação, do NRE de Guarapuava para a direção, se convocou o conselho escolar para tomar ciência a respeito do interesse demonstrado pela SEED para implantar um colégio militar no referido espaço, assim como se posicionar sobre tal debate. O conselho escolar foi unânime em se posicionar contrário a proposta, e utilizou os seguintes argumentos para questionar sobre a implantação e modificações na organização do colégio Manoel Ribas, conforme consta em ata n.07/2018: 
1) As informações sobre o funcionamento dessa proposta são insuficientes para que a decisão seja tomada em pouco tempo; 2) o perfil de nossos alunos não se enquadra nesse tipo de organização e teríamos um grande público que compõe a nossa comunidade escolar, que precisaria procurar outro local para tentar matricular-se; 3) a identidade do colégio, construída num processo histórico, cultural, seria quebrada pela imposição de normas específicas da educação militar, que não cabe ao nosso contexto; 4) considerou-se a importante mudança com a Constituição Federal de 1988 para abertura e implementação de gestão democrática nos colégios públicos, reforçada pela Lei de Diretrizes e Bases da Educação de 1996, que assegura a participação ampla, que envolve a liberdade de manifestação de professores, estudantes, comunidade externa, nas decisões que envolve o processo educativo escolar; 5 ) em nossa sociedade dinâmica, a escola não pode ficar alheia a essas contradições, se fechando em regime específico. Pelo contrário, consideramos que a escola é um espaço de formação humanizadora, e que é um lugar que precisa acolher trabalhar e valorizar todas diversidades de ideias e de posicionamentos;6) ainda não há clareza pedagógica para responder a comunidade com qual representamos.

Após isso, no primeiro semestre de 2019, foi convocada por lideranças políticas, que defendem a educação militar, uma audiência pública para tratar sobre a implantação de colégio militar em Guarapuava. Fato que mobilizou a comunidade escolar de vários colégios que compareceram fazendo suas manifestações de repúdio. Ainda mais que a notícia foi veiculada nos meios de comunicação local e nas redes sociais apresentada como uma demanda.

A audiência pública ocorreu na Câmara Municipal de Guarapuava e foi marcada por conflitos no próprio formato da audiência, pois representantes da comunidade escolar não teriam espaço para expor suas ideias, diante disso foi necessário que os representantes dos alunos e pais protocolassem pedido de manifestação para a mesa organizadora do evento, e diante da insistência e pressão da comunidade juntamente com dois representantes de mandatos populares na câmara de vereadores, se autorizou que três lideranças representantes (dois alunos e uma mãe de aluno) do Colégio Manoel Ribas tivessem a oportunidade de manifestar-se.

A programação da audiência contou com a exposição de representantes da Polícia Militar sobre o funcionamento de um colégio 
militar. Após tal exposição a comunidade presente poderia fazer questionamentos de forma escrita em que a mesa selecionou algumas questões para responder. Em exposição as lideranças que puderam se manifestar, em apenas alguns minutos, questionaram: A quem cabe discutir educação? Profissionais da educação ou da segurança pública? Porque os investimentos que serão disponibilizados para implantação de um colégio militar não podem ser distribuídos nas escolas públicas já existentes? Como será feito a inclusão dos alunos em colégio militar que tem como princípios a seleção? Se a comunidade escolar é contra de onde nasceu a necessidade de modificar a organização escolar do Manoel Ribas?

$\mathrm{Na}$ audiência pública a maioria dos posicionamentos de lideranças políticas e representantes do NRE de Guarapuava foi de que ainda não se tem uma definição de que será no Manoel Ribas ou em outro colégio, assim a comunidade escolar se pergunta: que garantias a comunidade tem de que seu posicionamento seja respeitado?

Diante disso, evidencia-se a correlação de forças entre a comunidade escolar, filhos de pais da classe trabalhadora no enfrentamento das forças dominantes capitalistas, representadas por políticos locais e regionais, que muitas vezes, sensíveis a questão eleitoral do voto acabam recuando em prol das demandas sociais.

\section{CONSIDERAÇÕES FINAIS}

A partir dos questionamentos feitos ao longo deste estudo, consideramos que os governantes que vem pleiteando escolas militares, o fazem dentro de uma agenda conservadora favorecida pelo contexto atual e tem como objetivo manter a ordem social vigente e a hegemonia política. E por mais que tal necessidade não seja advinda das comunidades locais, políticos e agentes privados fazem o papel de intermediários, produzindo argumentos de convencimento social, além do que utilizam como troca de favores entre aliados causando uma falsa impressão de que estão ofertando educação de qualidade para a população. Essa nova onda militarista ganha mais respaldo quando é reforçada por propagandas recentes que 
estão sendo veiculadas na mídia nacional com o apoio do governo federal e do próprio MEC.

O caso dos dois colégios citados nos dá elementos suficientes para analisar que os argumentos de convencimento para a transformação de colégios públicos em colégios militares são produzidos por parte de agentes externos à educação. E embora a comunidade encontre amparo jurídico para defender a manutenção da organização dos colégios públicos, e posicione-se contrária a proposta, isso não significa nenhuma garantia, pois a natureza do Estado nos moldes capitalista age de acordo com os seus princípios em favor da classe dominante. E se a proposta de colégios militares não está de acordo com a legislação brasileira que rege a educação, o Estado tão logo cria novas regulamentações para que esse modelo educacional pareça legal. Então, se buscarmos respostas a um dos questionamentos feitos ao longo deste estudo, se uma escola pode ser militar, basta olhar para a ação do estado brasileiro que tem encarado os problemas da educação pública como uma questão de gestão segurança e controle, e por mais que profissionais da educação se cerquem de medidas legais e a comunidade seja resistente, isso não representa nenhum impedimento para que o Estado realize.

Do ponto de vista da gestão, observamos inúmeros agravantes no sentido de pensar e organizar a escola, pois a proposta não exige a formação pedagógica estabelecida nas leis educacionais, ficando a gestão e orientação pedagógica a cargo de militares o que inviabiliza conquistas históricas constitucionais e legais da educação brasileira. Eis aí o equívoco político e social desses novos modelos de gestão da escola pública no Brasil.

Um dos argumentos para a implementação de colégios militares está pautado num discurso de que estas instituições vêm para combater os altos índices de violência, o que está em contradição com o que tem sido a prática no estado do Paraná, e demonstra a fragilidade da proposta, uma vez que o interesse demonstrado pelos NREs tem sido por colégios que estão localizados em áreas urbanas centrais. 
De maneira geral, novos modelos de gestão da educação pública a partir da imposição de normas da educação militar descaracterizam a organização já constituída ao longo do processo histórico e cultural de colégios públicos, além de selecionar o público a ser atendido por essas instituições, cobrar taxas pela oferta de atividades específicas e exigir uma rígida disciplina militar, aspectos que provocar a exclusão da classe trabalhadora de espaços escolares democráticos.

\section{REFERÊNCIAS}

BRASIL. Lei n. 9.394 de 20 de dezembro de 1996. Dispõe sobre as Diretrizes e Bases da Educação Nacional. Brasília: MEC, 1996.

BRASIL. Lei n. 8.069, de 13 de julho de 1990. Dispõe sobre o Estatuto da Criança e do Adolescente e dá outras providências. Diário Oficial da República Federativa do Brasil, Brasília, DF, 16 jul. 1990. Disponível em: HTTP://www.planalto.gov.br/ccivil_03/LEIS/L8069.HTM\#art266. Acesso em: 24 set. 2019.

CASTRO, N. M. B. de C. "Pedagógico" e "disciplinar": o militarismo como prática de governo na educação pública do estado de Goiás Brasília.Dissertação (Mestrado em Antropologia Social)- Universidade de Brasília, Brasilia/DF, 2016.

GUIMARÃES, P. C. P.; LAMOS, R. de A. C. Militarização das escolas da rede estadual de Goiás: a nova onda conservadora. Revista do Programa de Pósgraduação em Educação da Unochapecó,Revista Pedagógica,V.20, N.43, Jan./Abr. 2018. Disponível em:

https://bell.unochapeco.edu.br , revistas , pedagogica , article , download. Acesso em: 20 mai. 2019.

MARX, K.; ENGELS, F. A Ideologia Alemã. São Paulo: Boitempo, 2014.

MARX, K. Manuscritos econômico-filosóficos. São Paulo: Boitempo, 2010.

MÉSZÁROS, I. A educação para além do capital. Tradução de Isa Tavares.São Paulo: Boitempo, 2005.

MÉSZÁROS, I. A montanha que devemos conquistar: reflexões acerca do Estado. São Paulo: Boitempo, 2015.

OLIVEIRA, D. D. de O. As escolas militares: o controle, a cultura do medo e da violência. In: OLIVEIRA, I. C. de; SILVA, V. H. V. de F. (Org.). Estado de Exceção 
Escolar: uma avaliação crítica das escolas militarizadas. Aparecida de Goiânia: Escultura produções editoriais, 2016.

PONCE, A. Educação e luta de classes. 18ed. São Paulo: Editora Cortez, 2001. SAVIANI, D. Trabalho e educação: fundamentos ontológicos e históricos. Revista Brasileira de Educação, v. 12, n. 34, jan./abr. 2007, p. 152-180.

SAVIANI, D. Instituições escolares no Brasil: conceito e reconstrução histórica. In: NASCIMENTO, M. I. M.; SANDANO, W.; LOMBARDI, J. C.; SAVIANI, D. (Orgs.). Instituições escolares no Brasil: conceito e reconstrução histórica. Campinas, SP: Autores Associados, 2007. p. 3-27.

\section{SILVA, C. da A.; ARAUJO, E. R. A militarização das escolas públicas:} vantagens e desvantagens trazidas pela disciplina e hierarquia militar. Biblioteca digital de segurança pública: mai - 2018. Disponível em: https://acervodigital.ssp.go.gov.br/pmgo/. Acesso em: 15 abr. 2018.

SILVA, J. J. D. G. da. Militarização de escolas públicas: avanços ou retrocessos? In: OLIVEIRA, I. C. de; SILVA, V. H. V. de F. (Org.). Estado de Exceção Escolar: uma avaliação crítica das escolas militarizadas. Aparecida de Goiânia: Escultura produções editoriais, 2016.

TAVARES, F. M. M. Quem quer manter a ordem? A ilegalidade da militarização das escolas em Goiás. In: OLIVEIRA, I. C. de; SILVA, V. H. V. de F. (Org.). Estado de Exceção Escolar: uma avaliação crítica das escolas militarizadas. Aparecida de Goiânia: Escultura produções editoriais, 2016.

TONET, I. Métodocientífico uma abordagem ontológica. São Paulo: Instituto Lukács, 2013.

VELOSO, E. R.; OLIVEIRA, N. P. de. Nós perdemos a consciência?: apontamentos sobre a militarização de escola públicas estaduais de ensino médio no estado de Goiás. In: OLIVEIRA, I. C. de; SILVA, V. H. V. de F. (Org.). Estado de Exceção Escolar: uma avaliação crítica das escolas militarizadas. Aparecida de Goiânia: Escultura produções editoriais, 2016.

Recebido em: 11 de fevereiro de 2021.

Aprovado em: 12 de maio de 2021. Publicado em: 15 de julho de 2021. 